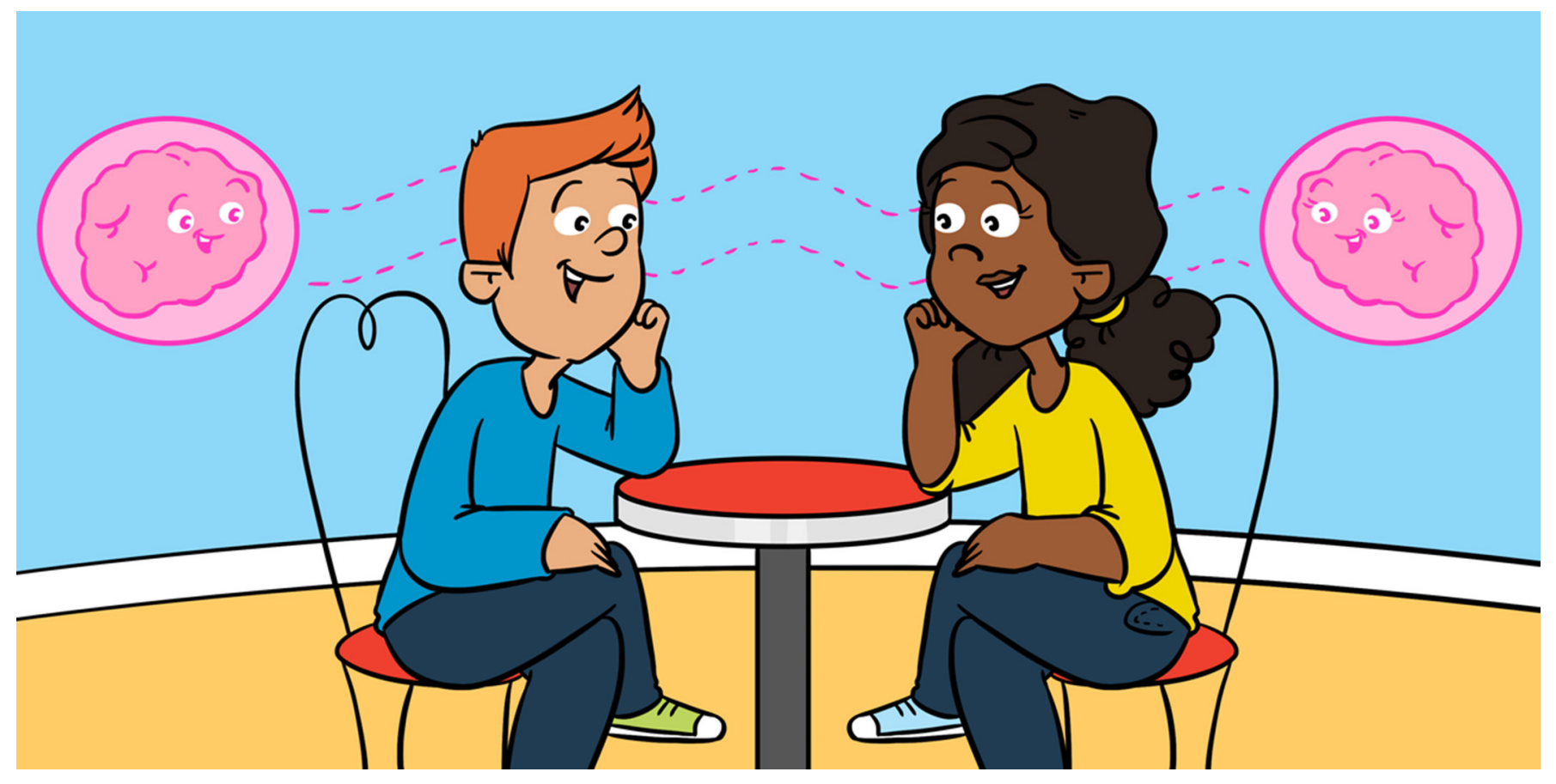

\title{
WHEN WE FEEL "LIKE-MINDED" IS IT ONLY IN OUR MINDS?
}

\author{
Inbal Ravreby ${ }^{1,2}$ and Yaara Yeshurun ${ }^{1,3 *}$ \\ ${ }^{1}$ School of Psychological Sciences, Tel Aviv University, Tel Aviv, Israel \\ ${ }^{2}$ Department of Neuroscience, Weizmann Institute, Rehovot, Israel \\ ${ }^{3}$ Sagol School of Neuroscience, Tel Aviv University, Tel Aviv, Israel
}

YOUNG REVIEWERS:

ISRAEL

I AS ARTS AND 回 SCIENCE

ACADEMY

AGES: 14-15
Much of our time is spent communicating with other people, including family, friends, and teachers. When we talk with others, we are interested in understanding one another, and we can often sense when the communication is good. Scientists suggest that synchronization-a state in which things happen simultaneouslycontributes to good communication. Research has found that synchronization in facial expressions, ways of speaking, body movements, pulse, breath, and even brain activity, are related to positive communication. In this article, we will describe the role of synchronization and discuss the possibility that when we feel we are "riding on the same wave" with the person we are talking to, we actually are on the same physical and mental wave-synchronized. 
Figure 1

Synchronization of behavior during a conversation. This photo illustrates the chameleon effect: as they communicate, the children unknowingly coordinate the way that they sit and their body language.

\section{SYNCHRONIZATION}

A state in which two things happen simultaneously, for example, two people smiling at the same time.

\section{CHAMELEON \\ EFFECT}

Non-conscious mimicry of interaction's partner body movements, facial expressions and ways of talking.

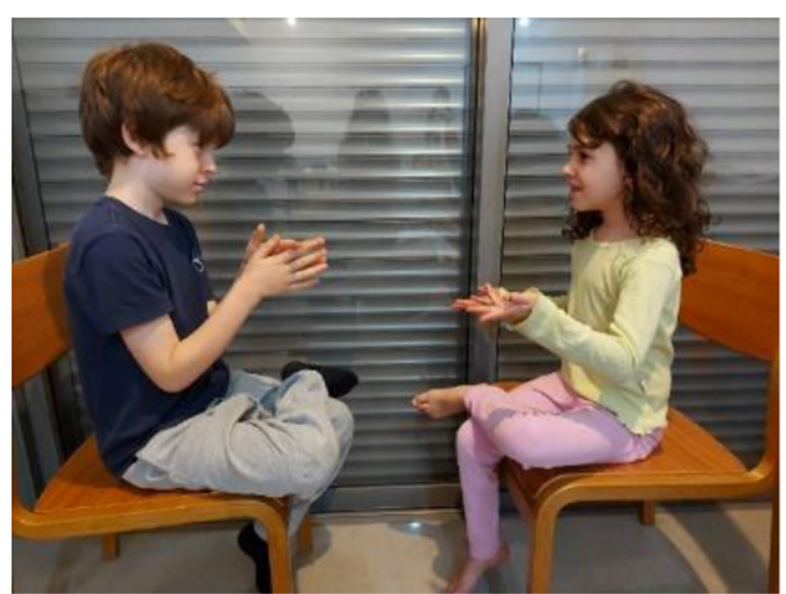

Figure 1

\section{THE CHAMELEON EFFECT}

Try this short experiment. Take a few minutes of your time to talk to someone who is at home with you. Tell that person about how you are feeling and what you have been doing today, and ask how he or she is feeling. During your conversation, notice both the facial expressions and body language that you and your conversation partner use. Did you smile at the same time? Did you sit or stand in the same position? Did you use similar tones of voice?

Studies have found that people often coordinate themselves with one another. For example, they walk at the same pace, use the same body postures (Figure 1), smile just moments apart, and slow down or speed up their speech depending on how fast the other person is talking. Even when we dance, our movements are influenced by the person we are dancing with, and those around us. This synchronization, in which people do things that are coordinated with others, begins when we are born. Infants often imitate the movements of those around them. For example, babies will stick out their tongues when they see their siblings do that, or they will open their mouths to eat when they see someone else eating.

Usually, all this coordination during communication happens without anyone even noticing! Researchers call this phenomenon the chameleon effect [1]-much like chameleons match their colors with their physical environments, we coordinate our behaviors to our social environments.

\section{SYNCHRONIZATION OF BEHAVIOR}

When we see someone smile, the muscles at the edges of our mouths and eyes move a little. Often, this is not visible from the outside, but it can be seen with a device that measures the electrical activity of 
IMITATION/MIMICRY

When a person performs the same action as another person, close together in time. For example, someone smiles and a bit later a person who sees them also smiles. the muscles. These muscle movements happen without our control, and, interestingly, the more we like the person we are talking with, the bigger the muscle movements are. When someone we like very much smiles, we will often smile back, without even noticing. This means that we coordinate ourselves more with people whose company we enjoy.

The positive influence of synchronization goes both ways: just as we more often imitate people we like than people we do not like, we also tend to like the people who imitate us more than those who do not. In one study, each participant collaborated with a researcher. With one group of participants, the researcher mimicked the participant: if the participant sat with one leg on top of the other, the researcher sat the same way; or if the participant touched his or her head, the researcher also did that. With the second group of participants, the researcher did not mimicked the participant. This study found that participants in the first group liked the researcher more than participants in the second group [1].

People who can "step into the shoes" of others and easily understand what others feel and think tend to mimic the facial expressions and body language of others more often. We are also more likely to trust and believe those people who mimic us. Surprisingly, this effect was even found with avatars - virtual characters in computer games. Study participants liked and believed avatars that mimicked them more than avatars that did not.

\section{SYNCHRONIZATION OF BODY AND BRAIN}

Synchronization and mimicry do not occur only with our behaviors, but also in our automatic body processes. For example, when people walked on coals - a very scary and exciting action-in front of their relatives, the people who felt closest to the coal walkers were highly synchronized with the walker's heartbeat, even though the relatives were only watching [2]. We also unknowingly mimic one another's breathing. In one experiment, participants watched a film. In parts where the film's hero took a long breath or sighed, the participants often mimicked that character and sighed just $1 \mathrm{~s}$ later.

Much evidence has been found showing that synchronization also happens at the brain level. For example, when watching short videos, the brain activity of friends is more synchronized than that of people who are not friends. It is possible that this happens because people who understand and interpret things in the same way have brain activity that is more similar. If two soccer players watch a dramatic match together, the brain of a fan of one team will be active similarly to the brains of other fans of that same team, and differently from the brains of fans supporting the opposite team. Similarly, if we listen to Harry Potter and imagine that we are Harry Potter, our brains will 
Figure 2

FNIRS is a technique that allows researchers to easily measure brain activity in the lab and during daily life, as can be seen in the picture. When participants play the mirror game, the more synchronized their movements, the more synchronized their brain activity in an area of the brain related to social interaction. An example of participants' brain responses can be seen in the right panel, in which in red is the response of one participant, and in blue the response of the other.

\section{MAGNETIC}

RESONANCE

IMAGING (MRI)

A technique that measures brain structure and activity in a great resolution. The participant must be lying inside the machine.

\section{FUNCTIONAL}

NEAR-INFRARED SPECTROSCOPY (FNIRS)

A technique that allows to measure brain activity in the outer parts of the brain and can be used during daily activities such as when having a conversation or playing together.

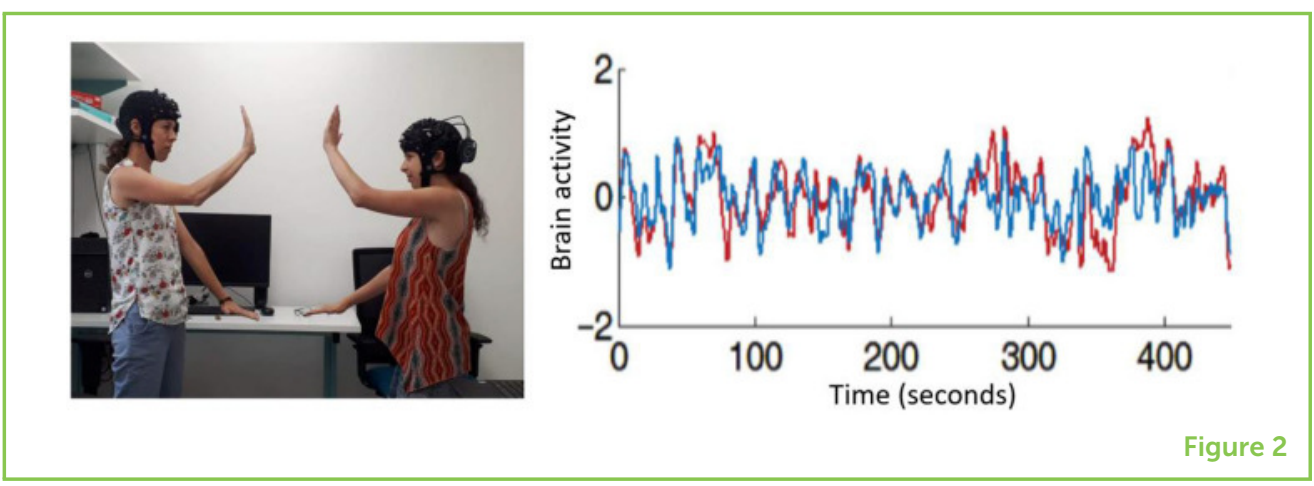

be synchronized with other people who imagine that they are Harry Potter, but not with those who imagine they are Voldemort.

Brain synchronization is also related to the amount of understanding between the speaker and listener. For example, a research participant told a story about something she experienced in high school, while her brain activity was measured using a device called a magnetic resonance imaging (MRI) scanner. Afterwards, other participants listened to the recording of her story while their brains were being scanned. The researchers found that people who had similar brain activity to that of the storyteller understood her story better [3].

One interesting study tested brain synchronization among students and the teacher during a class. The study found that the more interested and engaged the students were in the subject being taught, the more synchronized their brain activity was with that of other students and the teacher [4]. The next time you are interested in a class, remember that your brain is synchronized with the brains of the teacher and other interested students!

Synchronization of brain activity is also seen during other positive interactions, such as love between friends and partners, collaboration on a project, singing, and listening to enjoyable music. You can experience how enjoyable synchronization can be by playing the mirror game with a friend: stand in front of each other and try to move your arms in as coordinated a manner as possible. You will see that, when you succeed in moving your arms together, it feels very gratifying. This game was used in experiments measuring brain synchronization, using a technique called functional near-infrared spectroscopy (FNIRS), which involves wearing a device on the head (Figure 2). The results showed that when participants move in a more synchronized way, their brains are also more synchronized.

\section{HOW CAN SYNCHRONIZATION IMPROVE COMMUNICATION?}

So now you know that synchronization of behavior, body processes, and brain activity all help with effective communication. But why is this 
so? It is possible that synchronization helps us to better understand what another person is going through. For example, when someone else smiles it makes us smile, and if our brains interpret a smile as an indicator of happiness, this will help us to understand that the person in front of us is happy.

In a study conducted about 30 years ago, participants watched a funny television show. In parts of the show, researchers added the sound of people laughing. The research participants smiled more during the parts of the show that contained laughter, and also enjoyed these parts more. Interestingly, when participants were instructed not to move their face muscles during the show, they did not enjoy the parts with laughter more than other parts. This tells us that the act of smiling made participants enjoy the show more. Facial expressions and body movements seem to precede the feeling of happiness!

In addition to helping us understand what others are feeling, synchronization can make understanding another person easier. For example, when people coordinate the volume of their speech, the words and phrases they use, or their tone of voice with the person they are speaking with, it is easier for the listener to understand them, because coordinated speech is like using a common language. Synchronization of body movements helps us to feel connected to the person with whom we are communicating, and may lead us to help each other more. Research has found that if children seesaw together at the same pace in the playground, they are more likely to share with each other afterwards and collaborate on tasks. Another study found that when two rowers in a boat synchronized their body movements, they produced more mood-improving substances in their blood.

Together, these examples tell us that synchronization can facilitate understanding of one another and improve cooperation.

\section{INTERESTING QUESTIONS FOR THE FUTURE}

There have been some extraordinary scientific advances in recent years, including FNIRS, that can help us study real-world communication and measure the synchronization and imitation that happens during natural communication-not just in the lab. These new techniques will allow us to ask many fascinating questions about the various kinds of synchronization that occur in daily life. Are there certain people we tend to synchronize with more than others? Are certain types of synchronization more related to our emotional experiences than others-for example, is brain synchronization more related to understanding, and heartbeat synchronization more related to excitement? Is it possible to resolve conflicts using synchronization? If we create synchronization when two people first meet, will they have a greater chance of becoming friends? We plan to examine how various aspects of synchronization, including facial 
expressions, speech, heartbeat, breathing, and brain activity, influence communication in daily life. Our aim is to better understand the roles and importance of the various types of synchronization and learn how to use them to improve communication between people.

To summarize, if you have ever felt like you were "riding the same wave" as someone you were communicating with, or that you and your close friends are "like-minded," this was probably not by chance! Every day, as we communicate, we synchronize with other people-especially those we feel close to-often without even noticing.

\section{REFERENCES}

1. Chartrand, T. L., and Bargh, J. A. 1999. The chameleon effect: the perception-behavior link and social interaction. J pers Soc psychol. 76:893-910. doi: 10.1037//0022-3514.76.6.893

2. Konvalinka, I., Xygalatas, D., Bulbulia, J., Schjødt, U., Jegindø, E. M., Wallot, S., et al. 2011. Synchronized arousal between performers and related spectators in a fire-walking ritual. Proc Natl Acad Sci USA. 108:8514-9. doi: 10.1073/pnas.1016955108

3. Stephens, G. J., Silbert, L. J., and Hasson, U. 2010. Speaker-listener neural coupling underlies successful communication. Proc Natl Acad Sci USA. 107:14425-30. doi: 10.1073/pnas.1008662107

4. Dikker, S., Wan, L., Davidesco, I., Kaggen, L., Oostrik, M., McClintock, J., et al. 2017. Brain-to-brain synchrony tracks real-world dynamic group interactions in the classroom. Curr Biol. 27:1375-80. doi: 10.1016/j.cub.2017.04.002

SUBMITTED: 27 July 2021; ACCEPTED: 07 October 2021; PUBLISHED ONLINE: 08 November 2021.

EDITED BY: Idan Segev, Hebrew University of Jerusalem, Israel

CITATION: Ravreby I and Yeshurun Y (2021) When We Feel "Like-Minded" Is It Only in Our Minds? Front. Young Minds 9:748390. doi: 10.3389/frym.2021.748390

CONFLICT OF INTEREST: The authors declare that the research was conducted in the absence of any commercial or financial relationships that could be construed as a potential conflict of interest.

COPYRIGHT (c) 2021 Ravreby and Yeshurun. This is an open-access article distributed under the terms of the Creative Commons Attribution License (CC BY). The use, distribution or reproduction in other forums is permitted, provided the original author(s) and the copyright owner(s) are credited and that the original publication in this journal is cited, in accordance with accepted academic practice. No use, distribution or reproduction is permitted which does not comply with these terms. 

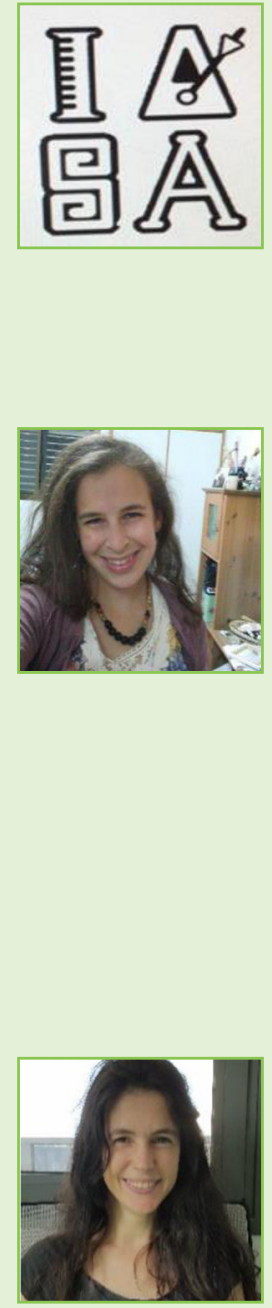

\section{YOUNG REVIEWERS}

\section{ISRAEL ARTS AND SCIENCE ACADEMY, AGES: 14-15}

Israel Arts and Science Academy is a place for curious students who like to learn. In the 9th grade, as part of the elective classes we are the students who read scientific papers we chose. The course was lead by Anat Maoz, the principle of our secondary school, which has a Masters degree in marine biology.

\section{AUTHORS}

\section{INBAL RAVREBY}

I was raised in Jerusalem. During my B.Sc., in psychology and cognition at the Open University, I got to know a variety of people. For many years, I wondered why there is an immediate social bonding with certain people, but with others the connection forms gradually or not at all. I do not know whether telepathy exists, but when people are close to one another, sometimes they can anticipate what the other would say, what they think, or how they feel. In my M.Sc., in neuroscience at the Weizmann Institute of Science, I focused on the question of how similarities in peoples' body odors influence social bonding. Today, for my Ph.D., in neuroscience at the Weizmann Institute of Science, I work with Prof. Noam Sobel and Dr. Yaara Yeshurun, studying how synchronization is related to closeness between people and to the feeling of shared understanding.

\section{YAARA YESHURUN}

I was raised in Givataim. In high school, I decided I wanted to study emotions-I thought it was to deal with the difficulty of being a soccer fan of Hapoel Tel Aviv, but years later I understood that it was my way of combining my mom's career (psychologist) and my dad's (computer scientist). I got a B.Sc., in biology and mathematics and an M.Sc., in biology; then I got a Ph.D., in neuroscience at the Weizmann Institute, studying the relationship between the sense of smell and memory. I did postdoctoral fellowship in the United States, studying how the brain response differ when people understand the same story in different ways. Today, I am a faculty member at the School of Psychological Sciences and the Sagol School of Neuroscience at Tel-Aviv University, in the field of social neuroscience. I try to be particularity in sync with my three children. *yaara.yeshurun@gmail.com 